\title{
WAKTU PENGGUNAAN DEPO MEDROXY PROGESTERONE ACETATE TERHADAP PENINGKATAN INDEKS MASSA TUBUH (IMT) IBU
}

\author{
Timing of Depro Medroxy Progesterone Acetate Against Increased \\ Body Mass Index (BMI) of Mother
}

\author{
Hadina, Hadriani, Kartini, Putri Nurul Sakinah \\ Poltekkes Kemenkes Palu \\ (email korespondensi: hadina1980@gmail.com)
}

\begin{abstract}
ABSTRAK
Depo medroxy progesterone acetate (DMPA) dapat menyebabkan penambahan Indeks Massa Tubuh (IMT). Tujuan penelitian ini untuk mengetahui pengaruh waktu penggunaan depo medroxy progesterone acetate terhadap peningkatan IMT. Desain penelitian observasional dengan pendekatan potong lintang. Penelitian dilaksanakan di Puskesmas Talise Palu Kecamatan Mantikulore Palu Sulawesi Tengah pada tanggal 0-31 Juli 2017. Populasi adalah seluruh wanita usia subur pengguna KB suntik 3 bulan dengan jumlah populasi 84 akseptor. Menggunakan rumus slovin diperoleh besar sampel sebanyak 69. Pengambilan sampel dengan teknik purposive sampling. Instrumen penelitian menggunakan kuesioner dan timbangan berat badan. Analisis data univariat dan bivariat. Analisis korelasi dan regresi linier sederhana menunjukkan pengaruh waktu penggunaan kontrasepsi DMPA terhadap peningkatan IMT memiliki hubungan signifikan p-value $<0,05$ dengan nilai koefisien korelasi 0,513 dengan hubungan yang kuat, dan nilai t hitung 4,886 lebih besar dari t tabel 1,996 ini berarti bahwa waktu penggunaan DPMA berpengaruh terhadap peningkatan berat badan. Persamaan regresi linier yang diperoleh adalah $\mathrm{Y}=-0,984+0,259$.X. dari penelitian ini dapat disimpulkan bahwa waktu penggunaan kontrasepsi DPMA berpengaruh terhadap peningkatan IMT ibu di Puskesmas Talise. Disarankan bagi bidan-bidan agar dapat memberikan konseling kepada akseptor tentang efek samping kontrasepsi, sehingga akseptor lebih selektif dalam memilih kontrasepsi.
\end{abstract}

Kata Kunci : Depo Medroxy Progesterone Acetate, Indeks Massa Tubuh

\section{ABSTRACT}

Depo medroxy progesterone acetate (DMPA) can cause an increase in Body Mass Index (BMI). The purpose of this study was to determine the effect of the use of depro medroxy progesterone acetate on increasing IMT. Observational research design with cross sectional approach. The study was conducted at the Talise Health Center in Palu, Mantikulore District, Palu, Central Sulawesi, on July 0-31, 2017. The population was all women of childbearing age who had 3 months of injecting birth control with a population of 84 acceptors. Using the Slovin formula, a sample size of 69 was obtained. Sampling with a purposive sampling technique. The research instrument used questionnaires and weight scales. Univariate and bivariate data analysis. Correlation analysis and simple linear regression showed the influence of the time of use of DMPA contraception to increase $B M I$ has a significant relationship p-value $<0.05$ with a correlation coefficient of 0.513 with a strong relationship, and the $t$ value of 4.886 is greater than t table of 1.996 this means that the time DPMA use has an effect on weight gain. The linear regression equation obtained is $Y=-0,984+0,259 . X$. From this study it can be concluded that the use of DPMA contraception affects the increase in maternal IMT at Talise Health Center. It is recommended for midwives to be able to provide counselors to acceptors about the side effects of contraception, so that acceptors are more selective in choosing contraception

Keywords : Depo Medroxy Progesterone Acetate, Body Mass Index 


\section{PENDAHULUAN}

Di Indonesia, tren pemakaian kontrasepsi meningkat dari 50\% pada SDKI 1991 menjadi $62 \%$ pada SDKI 2012. Angka pemakaian alat/cara $\mathrm{KB}$ meningkat hampir $1 \%$ per tahun selama periode sebelas tahun antara SDKI 1991 dan SDKI 2002-2003 dengan presentase pil $13,6 \%$, IUD $3,9 \%$, suntik $31,9 \%$, kondom $1,8 \%$, implant $3,3 \%$, mow $3,2 \%$, mop $0,2 \%$, pantang berkala $1,3 \%$ dan senggama terputus 2,3\% ${ }^{1}$. Data Dinas Kesehatan Propinsi Sulawesi Tengah pada bulan JanuariDesember 2015 tercatat pasangan usia subur (PUS) sebanyak 535.146 dan jumlah akseptor KB aktif sejumlah 336.808 akseptor. Adapun jenis kontrasepsi yang paling banyak digunakan yaitu kontrasepsi suntik sebesar 139.195 akseptor $(41 \%)^{2}$. Data Dinas Kesehatan kota Palu peserta KB aktif pada bulan Januari-Desember 2015 tercatat PUS sebanyak 61.133 jiwa, peserta KB aktif berjumlah 32688 akseptor. Peserta KB yang paling banyak adalah suntik sebanyak 10.078 akseptor ${ }^{3}$.

Sebagian besar peserta KB menggunakan kontrasepsi jangka pendek yang membutuhkan pembinaan secara rutin dan berkelanjutan untuk menjaga kelangsungan pemakaian kontrasepsi. Proporsi metode kontrasepsi jangka pendek yang banyak digunakan berdasarkan data yang diperoleh adalah alat kontrasepsi suntik. Oleh karena depo medroxy progesterone acetate (DMPA) mudah didapatkan ${ }^{2}$.

Depo medroxy progesterone acetate memiliki kelebihan dan kekurangan. Kelebihan dari kontrasepsi suntik yaitu sangat efektif, tidak memiliki pengaruh terhadap produksi air susu ibu (ASI), klien tidak perlu menyimpan obat suntik, tidak berpengaruh pada hubungan suami istri, mencegah beberapa penyebab penyakit radang panggul. Sedangkan kekurangan dari kontrasepsi suntik yaitu sering ditemukan gangguan haid, tidak dapat dihentikan sewaktu-waktu sebelum suntikan berikutnya, tidak menjamin perlindungan terhadap penularan infeksi menular seksual, terlambatnya kembali kesuburan, dan peningkatan berat badan ${ }^{4}$.

Kontrasepsi suntik adalah salah satu jenis kontrasepsi hormonal yang memiliki berbagai efek samping. Salah satu efek samping jika digunakan dalam jangka waktu yang lama adalah kenaingkatan berat badan. Hal ini dikaitkan dengan adanya efek progestin yang menyebakan retensi cairan ${ }^{5}$. Menurut para ahli, kontrasepsi suntik merangsang pusat pengendali nafsu makan di hipotalamus sehingga menyebabkan akseptor makan lebih banyak dari biasanya sehingga menyebabkan para akseptor KB suntik mengalami obesitas ${ }^{5}$.

Perubahan berat badan yang mengarah pada peningkatan berat badan akan mempengaruhi body image seseorang. Selain itu juga berdampak pada munculnya penyakit degeneratif misalnya penyakit jantung, darah tinggi, juga berpengaruh pada aktivitas keseharian. Orang gemuk biasanya mudah lelah, mudah mengantuk, dan lamban dalam beraktivitas ${ }^{5}$.

Sebuah penelitian yang dilakukan oleh Rahmawati dengan judul "Hubungan lama pemakaian KB suntik DMPA dengan peningkatan berat badan" yaitu, Jika menggunakan kontrasepsi suntik DMPA dalam waktu lama bisa mengakibatkan IMT kira-kira 1-2 $\mathrm{kg}$ pada tahun pertama dan kira-kita 4-10 kg jika digunakan sekitar 3-5 tahun ${ }^{6}$. Menurut penelitian di Texas "Relationship of injectable contraception with weight gain" Akseotor pengguna depo medroxy progesterone acetate atau suntik KB 3 bulan, sebagian besar bertambah IMT nya sebesar 11 pon atau 5,5 kilo gram dan terjadi penimbunan lemak badan sekitar 3,4 persen selama tiga tahun pemakaian ${ }^{7}$.

Data dari Puskesmas Talise pada bulan November 2016 menunjukkan bahwa peserta KB aktif 2.191 akseptor dengan rincian yaitu peserta KB suntik 950 orang, IUD 583 orang, pil 386 orang, implant 235 orang, kondom 26 orang, mow 11 orang dan MOP 0 orang. Yang berkunjung pada bulan Januari-Desember 2016 dan Januari-Februari 2017 menunjukkan penggunaan $\mathrm{KB}$ suntik 3 bulan sebanyak 84 akseptor ${ }^{8}$.

Tujuan penelitian untuk mengetahui pengaruh waktu penggunaan depo medroxy progesterone acetate terhadap Peningkatan Indeks Massa Tubuh lbu di Puskesmas Talise.

\section{METODE PENELITIAN}

Desain penelitian menggunakan observasional analitik dengan pendekatan Potong lintang. Bertempat di wilayah Puskesmas Talise Palu Kecamatan 
Mantikulore pada tanggal 03-31 Juli 2017. Populasi adalah seluruh wanita usia subur pengguna $\mathrm{KB}$ suntik 3 bulan dengan jumlah populasi 84 akseptor. Dari perhitungan rumus slovin didapatkan jumlah sampel sebanyak 69 orang. Pemilihan pengambilan sampel digunakan purposive sampling ketentuan: tidak sedang menggunakan obat pelangsing, tidak menderita penyakit kronis, menggunakan kontrasepsi DMPA secara terus menerus sampai penelitian selesai. Pengumpulan data melalui wawancara langsung menggunakan kuesioner dan penimbangan berat badan. Analisis univariat digunakan distribusi frekuensi. Uji statistik simple linier regression dengan tingkat kesalahan $5 \%(\alpha=0,05)$ dan tingkat kepercayaan 95\%. Data akan disajikan dalam tabel disertai penjelasan.

\section{HASIL}

Hasil penelitian ini diperoleh melalui penimbangan berat badan sebelum dan sesudah menggunakan kontrasepsi DMPA. Berat badan sebelum diambil dari kartu KB ibu dan berat badan sesudah dengan melakukan penimbangan berat badan secara langsung serta mengajukan beberapa pertanyaan. Adapun analisis univariat adalah:

Tabel 1. Waktu Penggunaan dan perubahan IMT pengguna DMPA di Puskesmas Talise

\begin{tabular}{lccccc}
\hline \multicolumn{1}{c}{ Karakteristik } & n & Min-max & Mean \pm SD & p-value & r \\
\hline Waktu Penggunaan DMPA (bulan) & 69 & $6-36$ & $14,7 \pm 7,4$ & & \\
\hline Perubahan IMT & 69 & $-10,0-12$ & $2,84 \pm 3,7$ & 0,000 & 0,513 \\
\hline
\end{tabular}

Sumber: Data primer 2017

Berdasarkan tabel 1, waktu penggunaan DMPA maksimal 36 bulan dan rata-rata 14,7 bulan. Data yang diperoleh bahwa peningkatan berat penambahan IMT minimal $-10,0$ maksimal 12 dan rata-rata 2,84. Berdasarkan tabel 3 menunjukan bahwa koefisien korelasi $(\mathrm{r})=0,513$; dengan nilai $\mathrm{p}=0,000 \leq 0,05$ sehingga dapat disimpulkan bahwa hubungan kedua variabel sangat signifikan atau ada pengaruh waktu penggunaan Kontrasepsi DMPA terhadap Peningkatan IMT di Puskesmas Talise. Sementara dari nilai koefisien r 0,513 berada di range 0,51-0,75 yang menunjukan adanya hubungan positif yang kuat, sehingga dapat disimpulkan bahwa terdapat pengaruh waktu penggunaan Kontrasepsi DMPA terhadap Peningkatan IMT. Peningkatan IMT memiliki hubungan yang kuat. Nilai $R$ square $=0,263$, yang artinya waktu penggunaan Kontrasepsi DMPA memberikan kontribusi terhadap peningkatan berat badan sebesar $26,31 \%$ dan selebihkan dipengaruhi oleh faktor lain yang tidan dianalisis.

Dapat dilihat bahwa $t_{\text {tabel }} 1,996$ lebih kecil dari $\mathrm{t}$ hitung 4,886 maka Ho di tolak, bermakna bahwa ada pengaruh yang kuat antara waktu penggunaan Kontrasepsi DMPA terhadap Peningkatan IMT, maka persamaan regresi linier sederhana yang diperoleh adalah sebagai berikut $Y=-0,984+0,259 \mathrm{X}$. Hal ini disimpulkan bahwa peningkatan IMT akan bertambah 0,259 bila lama pemakaian bertambah setiap bulan.

\section{PEMBAHASAN}

\section{Waktu Penggunaan Kontrasepsi Berdasarkan Karakteristik Responden}

Menurut Siswosudarmo dkk dalam Sriwahyuni bahwa usia paling sehat untuk hamil, bersalin serta menyusui adalah pada usia 20-35 tahun. Pada umur $>35$ tahun memiliki risiko yang banyak untuk hamil dan bersalin. Hasil penelitian ini menunjukan bahwa akseptor kontrasepsi suntik 3 bulan di Puskesmas Talise paling banyak berusia 20-35 tahun dan menjadi usia reproduksi sehat dan sangat dianjurkan untuk menggunakan kontrasepsi ${ }^{9}$.

Berdasarkan uraian dari beberapa teori peneliti berpendapat bahwa umur 20 sampai 35 tahun merupakan usia sangat minimal risiko terhadap maternal pain and death sehingga merencanakan dan mengatur kehamilan di usia ini dengan $\mathrm{KB}$ meminimalkan kematian maternal pada bayi. Program KB ini akan berkontribusi untuk kelangsungan hidup ibu dan bayi.

Ibu Rumah tangga merupakan sebagian besar pekerjaan akseptor kontrasepsi suntik 3 
bulan di Puskesmas Talise dan yang paling sedikit adalah honorer. Pekerjaan peserta KB DMPA sebagai URT menjadi salah satu penyebab terjadinya kenaikan berat badan karena kurangnya aktifitas mereka. Hal ini cocok dengan teori Suratun bahwa efek samping dari suntik DMPA adalah depresi yaitu rasa lesu, tidak bersemangat untuk bekerja dan melakukan aktifitas sehari-hari ${ }^{10}$.

Maka peneliti berpendapat bahwa ibu-ibu yang memiliki pekerjaan URT dapat mengalami kenaikan berat badan karena kurangnya aktivitas yang dilakukan dan lebih banyak menghabiskan waktu dirumah, sehingga kandungan hormon yang ada pada kontrasepsi suntik 3 bulan menyebabkan bertambahnya nafsu makan, menyimpan banyak karbohidrat dan tidak terjadi proses pembakaran dalam tubuh.

\section{Pengaruh Waktu penggunaan Kontrasepsi DMPA terhadap Peningkatan IMT}

Berdasarkan hasil penelitian memperlihatkan bahwa ada pengaruh yang signifikan waktu penggunaan Kontrasepsi DMPA terhadap Peningkatan IMT. Peneliti berpendapat bahwa responden mengalami perubahan IMT disebabkan adanya perubahan hormon progestin yang dapat menimbulkan retensi cairan dalam tubuh.

Hasil penelitian ini sejalan dengan teori Hartanto yang mengatakan bahwa hormon progesteron yang ada dalam kontrasepsi suntik 3 bulan merangsang pusat pengendalian di hypotalamus mengakibatkan keinginan yang kuat untuk mengonsusmsi makanan meningkat dari kebiasaan sebelumnya. Teori ini diperjelas oleh Glasier yang mengatakan mengkonsumsi banyak makanan menyebabkan meningkatnya timbunan simpanan lemak. Meningkatnya hormon progestin memudahkan perubahan karbohidrat dan gula menjadi lemak, sehingga lemak di bawah kulit bertambah ${ }^{12}$.

Data ini njuga cocok dengan data yang disampaikan oleh Moloku tentang hubungan lama pemakaian kontrasepsi suntik 3 bulan dengan perubahan berat badan di Puskesmas Ranomuut Manado yang mengatakan ada hubungan yang signifikan antara lama pemakaian DMPA dengan perubahan IMT dikarenakan kontrasepsi DMPA menyebabkan Kenaikan IMT lebih cepat dibandingkan dengan tidak menggunakan alat kontrasepsi suntik 3 bulan ${ }^{13}$.
Penelitian ini diperkuat hasil penelitian Purnamasari yang mengatakan ada hubungan lama pemakaian DMPA terhadap penambahan IMT dikarenakan kandungan hormon progestin dapat meningkatkan nafsu makan bertambah apabila pemakaian dosis yang tinggi dalam waktu lama karena dapat mempengaruhi saraf pusat di hipotalamus yang berakibat peserta KB mengonsumsi makanan tidak seperti biasanya $^{14}$. Hal ini sejalan dengan hasil penelitian Sutriani yang menunjukkan adanya hubungan pemakaian DMPA terhadap perubahan berat badan ${ }^{15}$.

Berdasarkan teori dan hasil penelitian yang ada, ibu yang menggunakan KB DMPA berpeluang lebih besar mengalami kenaikan berat badan dibandingkan dengan ibu yang tidak menggunakan KB DMPA. dikarenakan hormon progesteron yang ada dalam DMPA memengaruhi nafsu makan yang ada di hypotalamus sehingga ibu tidak dapat mengontrol porsi makannya yang menyebabkan peningkatan berat badan berlangsung lebih cepat dari pada biasanya. Selain itu kenaikan IMT juga dikaitkan dengan Ras. Mengkonsumsi banyak serat dalam diet dapat mencegah penambahan berat badan.

\section{KESIMPULAN DAN SARAN}

Waktu penggunaan Kontrasepsi DMPA berpengaruh terhadap Peningkatan IMT. Diharapkan bagi bidan-bidan agar dapat memberikan konseling kepada akseptor tentang efek samping kontrasepsi, sehingga akseptor lebih selektif dalam memilih kontrasepsis.

\section{DAFTAR PUSTAKA}

1. Kemenkes RI. 2013. Survei Demografi Kesehatan Indonesia Tahun 2012. Jakarta

2. Dinas Kesehatan Provinsi Sulawesi Tengah. 2015. Laporan PWS KIA Provinsi Sulawesi Tengah tahun 2015. Sulawesi Tengah

3. Dinas Kesehatan Kota Palu. 2015. Laporan PWS KIA Kota Palu tahun 2015. Palu

4. Sulistyawati, A. 2012. Pelayanan Keluarga Berencana. Salemba Medika; Jakarta

5. Hadina, 2016. Hubungan Pemakaian kontrasepsi Hormonal terhadap perubahan Berat badan Akseptor KB. UNPAD. Bandung. Proceeding (hlm 683-687).

6. Rahmawati, E dan Khusnal, E. 2012. Hubungan Lama Pemakaian KB Suntik DMPA Dengan Peningkatan Berat Badan 
Pada Akseptor Di Puskesmas Mergangsan Kota Yogyakarta Tahun 2012. Stikes Aisyiyah Yogyakarta (Online). (Diakses pada 12 mei 2016)

7. Susila, I dan Oktaviani, T, R. 2015. Hubungan Kontrasepsi Suntik Dengan Peningkatan Berat Badan Akseptor. Universitas Islam Lamongan (Online). (Diakses pada 06 desember 2016)

8. Puskesmas Talise. 2016. Laporan Kunjungan KB. Puskesmas Talise

9. Sriwahyuni, Efi. 2012. Hubungan Antara Jenis Dan Lama Pemakaian Alat Kontrasepsi Hormonal Dengan Peningkatan Berat Badan Akseptor. Universitas Airlangga (Online). (Diakses pada 01 agustus 2017)

10. Suratun. 2013. Pelayanan Keluarga Berencana dan Pelayanan Kontrasepsi. Trans Info Media; Jakarta

11. Hartanto, Hanafi. 2010. Keluarga Berencana dan Kontrasepsi. Pustaka Sinar Harapan: Jakarta
12. Glasier, Anna dan Ailsa Gebbie. 2011. Keluarga Berencana dan Kesehatan Reproduksi. Jakarta: EGC

13. Moloku, M. dkk. 2016. Hubungan Lama Pemakaian Lama Kontrasepsi Suntik 3 Bulan Dengan Perubahan Berat Badan Di Puskesmas Ranomuut Manado. Universitas Sam Ratulangi Manado (Online). (Diakses pada 06 desember 2016)

14. Purnamasari, D. 2009. Hubungan Lama Pemakaian KB Suntik Depo Medroksi Progesteron Asetat (DMPA) dengan Perubahan Berat Badan di BPS (Bidan Praktik Swasta) Yossi Trihana Jogonalan Klaten (Online). (Diakses pada 15 desember 2016)

15. Sutriani, dkk. 2015. Hubungan Penggunaan KB Suntik3 Bulan (DMPA) Dengan Kenaikan Berat Badan Di Puskesmas Cendrawasih Kota Makassar. STIK Makassar (Online). Diakses pada 18 Januari 2017. 